Volume 9, No.1.4, 2020

International Journal of Advanced Trends in Computer Science and Engineering

Available Online at http://www.warse.org/IJATCSE/static/pdf/file/ijatcse8291.42020.pdf

https://doi.org/10.30534/ijatcse/2020/8291.42020

\title{
A Review on Techniques to Improve the Cell Edge Performance for Wireless Networks
}

\author{
Nur Syazwani Mustaffa ${ }^{1}$, Wan Norsyafizan W. Muhamad ${ }^{2}$, Aliya Syahira Mohd Anuar ${ }^{3}$ \\ ${ }^{1}$ Faculty of Electrical Engineering \\ UiTM Shah Alam, Malaysia \\ waniemstffa@yahoo.com.my \\ ${ }^{2}$ Faculty of Electrical Engineering \\ UiTM Shah Alam, Malaysia, \\ syafizan@salam.uitm.edu.my \\ ${ }^{3}$ Faculty of Electrical Engineering \\ UiTM Shah Alam, Malaysia, \\ aliyasyahira93@gmail.com
}

\begin{abstract}
Massive increase demand to support higher data rates for broadband services like online gaming, video on demand $(\mathrm{VoD})$, triple play over wireless networks requires higher data rates. In wireless networks, the received signal power decrease as the propagation distance increase. This results in the following data rate coverage behavior where users at the center-region experienced excellent QoS performance. However, in cell edge region, user experience poor QoS where the spectral efficiency and power efficiency are very low. This is due to low received signal and high fading effects where cell-edge user is far away from Access Point (AP). Due to this scenario, various techniques have been present but there are still some challenges that have not been adopted by previous researches. This paper presents A Review on Techniques to Improve the Cell Edge Performance for Wireless Networks. In this paper, review of published researches starting from 2015 onwards that focus on improvement of cell edge performance is presented. The study can be divided into two parts which are techniques for cell edge improvement over cellular networks and WLAN respectively. In the literature, there are numerous approaches by previous researchers to achieve a better performance of cell edge user's over cellular networks: such as Cooperative Transmission Scheme, Packet Scheduling, Soft Frequency Reuse and Downlink Optimal Power Allocation Scheme. While in Wireless LAN, there are only several work that have been done, and most of the approach focus on link adaptation technique. In order to solve the cell-edge issue in WLAN, the author proposed Adaptive Modulation Coding and Scheme for IEEE 802.11ac.
\end{abstract}

Key words: cell edge, QoS, Cooperative Transmission Scheme, Packet Scheduling, Soft Frequency Reuse and Downlink Optimal Power Allocation Scheme, Adaptive Modulation Coding and Scheme

\section{INTRODUCTION}

Wireless networks are part of the important things and popular in today's world due to the advantages that it can offers to user such as user mobility, fast and simple installation, flexibility, scalability, etc. [1]. Rapid growth of networks that increase the data rate, led to a lot of techniques to boost the performance of wireless network communication [2]. In this study, wireless networks refer to both cellular and WLAN. Cell edge region is a network located on the periphery of a centralized network. User in center-region experienced excellent QoS performance. However, in cell edge region, user will experience poor QoS where the system performances deteriorated. At the cell edge region or at the cell boundary, the spectral efficiency and power efficiency are very low [3]. This is due to low received signal and high fading effects where cell-edge user's is far away from Access Point (AP). Due to this scenario, researches proposed techniques have been proposed to solve the problem but there a still some challenges that have not been adopted by previous researches.

Researchers proposed numerous of techniques that can improve the QoS performance for cell-edge users [4]. For cellular network, the works proposed Modified Largest Weighted Delay First [5],[6], Transmission Power Control Link Adaptation [7],[8], Packet Scheduling [9],[10], and Soft Frequency Reuse [11],[12]. Only the research work in [13] focused on improving the QoS of the cell edge region for wireless local area network where the author proposed Dynamic Transmit Power Control (DTPC).

Based on the previous researches, most of the techniques were focusing on cellular network and there is only one technique proposed for Wireless LAN. To fill the gap, the adaptive Modulation and Coding Scheme (AMCS) which adapt the transmission data rate for IEEE 802.11ac standard will be proposed which aims to boost the cell edge performance for Wireless LAN. 
Issue regarding the performance in cell-edge region has been an interesting topic among the researchers. In order to identify and understand the issue, review of cell-edge in WLAN has been studied. The study is then will be extended to determine the technique that is suitable to solve the problem. This research targets to improve the QoS for cell-edge region by using Adaptive Modulation Coding Scheme or Link Adaptation. The system capacity can be improved where the transmission of signal can be modified to account for the signal quality variation through this Link Adaptation technique. The user in cell-edge region experienced poor QoS due to low received signal, thus the proposed algorithm will adapt the transmission data rate based on SNR value. As SNR deteriorated which specify user at the cell edge, the transmission data rate will be adapted to a much higher level. Higher modulation scheme will provide a good radio channel, where higher amount of throughput can be achieved.

\subsection{Cellular Network}

Cellular network is a communication network where a radio network distributed over land via cells. A cellular network is made up of a number of radio cells. In a cellular cell, there is at least one fixed location base transceiver station (BTS) located at the center and a number of mobile users to communicate to each other via BTS.

Cell area consist of center and edge region [14]. Cell-center user's experience good QoS and high data rate due to high received signal and low fading effects [15]. Meanwhile, users at the cell-edge area experience poor QoS and low data rate due to low received signal and high fading effects.

The world is experiencing extreme urbanization as the global society is predicted to be twice the number in year of 2050 , thus further technological break-through is required to serve the society [16]. The requirement for high speed data has result in a rapid growth of cellular access technology, where this technology has become the most important needs of human daily life [17]. It is said that around six billion humans will use the Internet by 2015 [18].

Cellular concept Generation (G) was first introduced first generation (1G) in year 1979 following the second generation $(2 \mathrm{G})$ in 1991. Third generation (3G) technology was then introduced in 1998 and the fourth generation $(4 \mathrm{G})$ in year 2011. The next and latest generation which is $5 \mathrm{G}$ will be launched soon and it provides data rates up to 1Gbps [19]. Each of these generation has its own standards, specialties along with new features [20].

\subsection{Wireless Local Area Network (WLAN)}

Wireless Local Area Network (WLAN) is a wireless computer network where devices are linked to connect and communicate wirelessly within a restricted area. Even though WLAN geographically coverage is limited, it still can provide enrich bandwidth to the user [21]. The major difference between these two networks is how the data being transmitted.
For Local Area Network, data is transmitted through physical cables in a series of Ethernet packets while for WLAN, data transmitted over the air using one of Wi-Fi 802.11 protocols [22].

The abilities of IEEE 802.11 WLAN to increase mobility of ease, decrease installation and maintenance cost and improve flexibility has make it popular in communication technology [23]. There are several specifications in IEEE 802.11 families which are $802.11 \mathrm{a} / \mathrm{b} / \mathrm{g}, 802.11 \mathrm{n}, 802.11 \mathrm{ac}$ and the latest is 802.11ax [24]. First standard of IEEE 802.11 was launched in 1997 and the most famous standard is IEEE $802.11 \mathrm{a} / \mathrm{b} / \mathrm{g}$ where it uses $11 \mathrm{Mbps}$ transmission [25]. The capability of transmissions for this standard is up to $54 \mathrm{Mbps}$ and operates at $5 \mathrm{GHz}$ band [26].

IEEE 802.11n standard improves the performance of WLANs standard development [27]. In order to provide better performance, there are new features that have been incorporated into this standard which are; implementation of OFDM, introduction of MIMO, MIMO power saving, wider channel bandwidth, antenna technology and improve the data throughput by reducing the support for backward compatibility.

The increment of data rate can be improved with the use of IEEE 802.11ac standard where it provides a number of functions and parameters. 802.11ac operates in the $5 \mathrm{GHz}$ signal range and considers the traditional WLAN frequencies below $6 \mathrm{GHz}$. With this speeds, users are able to transfer large files very quickly or able to download and watch $\mathrm{HD}$ video [28]. IEEE 802.11ac provides higher modulation and coding scheme, wider channel bandwidth, system performance, backward compatibility, beam forming and multi-user performance [29].

IEEE 802.11ax is the new amendment that will improve four times of data throughput [30]. It is the newest Wi-Fi designed to address connectivity issues for high density networks. It provides higher throughput as well as improving the crowded environments performance. 802.11ax standard is designed for dense scenarios [31].

\section{EXISTING TECHNIQUES}

High data rates demand by consumers has been increasing day by day [32]. Wireless network has become pervasive and dense as per user's demanding [33]. Even though the technologies have been much improved to meet with the user demands, cell-edge user still experienced poor QoS due to low data rate, high latency and various fading effects [34]. Due to this issue, researches come out with number of techniques to solve the network performance issue. In edge area, as the distance between base station (BS) and mobile terminals (MTs) increases, power of radio signal decrease. Users in cell 
center region which is near to the $\mathrm{BS}$ achieve higher data rates compare to users in cell edge region [35]. Based on the research outcomes, numerous techniques have been proposed. Figure 3 below show the taxonomy of the proposed technique. In cellular network, different researchers proposed Modified Largest Weighted Delay First, Transmission Power Control Link Adaptation, Packet Scheduling, and Soft Frequency Reuse techniques. While in wireless LAN, researcher proposed Dynamic Transmit Power Control. Most of these techniques were focusing on improving the throughput, Quality of Service (QoS), delay and spectral efficiency of the user in cell edge region. Following section discuss each of the approach in details.

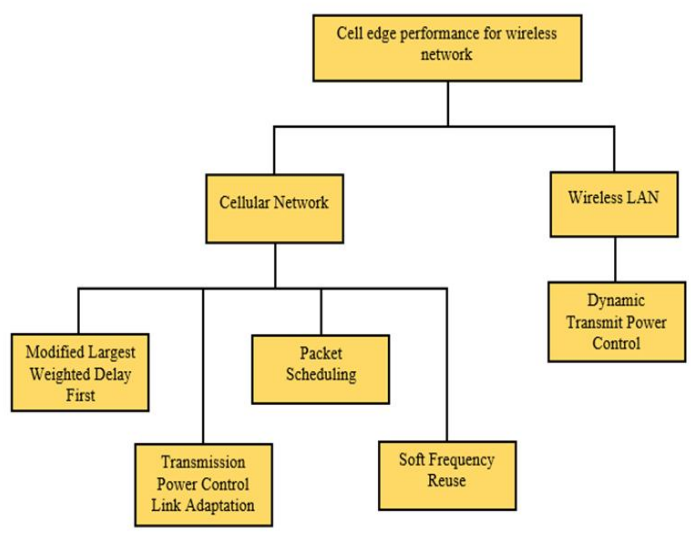

Figure 1: Taxonomy of cell edge performance for wireless network.

\subsection{Techniques in Cellular Networks}

Cell-edge performance issue in cellular networks has been an interesting topic in literature. Researchers proposed quite a number of techniques to improve the performance especially in terms of Quality of Service (QoS) especially on throughput, delay and spectral efficiency. This section summarized the previous researches that focus on cell-edge performances.

\section{A. Extending Modified Largest Weighted Delay First}

Hasibur R. C. in paper Enhanced Quality of Service of nCell-Edge User by Extending Modified Largest Weighted Delay First Algorithm in LTE Networks proposed extended Modified Largest Delay First technique to provide a good service to cell-edge user. As the Conventional Modified Largest Weighted Delay First (MLWDF) algorithm cannot solve the cell-edge issue due to it does not consider the user's location, they proposed an extended MLWDF (EMLWDF) to improve cell-edge user's performance. This algorithm consider the instantaneous channel quality perceived by user and packet queuing delay thus a good system performance can be achieved [36].
In this paper, they used block error rate (BER) and Signal-to-Interference ratio (SIR) as method of adaptation. The EMLWDF technique prioritize user in edge region by considering the downlink Signal-to-Interference plus Noise Ratio (SINR), distance between user and eNodeB along with HOL packet delay and the previous throughput. Therefore, cell-edge users will be given priority thus get a high number of resource blocks (RB). In order to use the link qualities, traffic demands, potential QoS requirement, RB must be assigned and schedule to the user [37]. They achieved 56.23\% of cell-edge performance compared to the Proportional Fairness and Modified Largest Weighted Delay First algorithm. The simulation result also shows that, as the throughput of cell-edge users increased, the average user throughput increased with overall $23.25 \%$.

Himani L., in paper A Quality of Service (QoS) Aware Scheduling Algorithm to Boost QoS of Cell-Edge Users in LTE Networks proposed Improved Extended Modified Largest Weighted Delay First (IE-MLWDF). This technique enhance throughput and QoS performance of user in edge region. Scheduling uses its policies to allocate portion of available spectrum [38]. The comparison is made between IE-MLWDF with the previous versions in terms of parameters where it considered parameters like cell edge throughput, end to end delay, Packet Loss Ratio (PLR), spectral efficiency and effects of changing user speed and operating frequency.

The proposed algorithm is a QoS aware algorithm where it is an improvement version of E-MLWDF and the scheduling algorithm that has concern with delay threshold of users, HOL delay. It enhanced cell edge throughput and spectral efficiency by $50.122 \%$ and $3.462 \%$ respectively and it also reduces PLR and end to end delay by $24.22 \%$ and $43.971 \%$ respectively. It concluded that IE-MLWDF provides better performance compared to E-MLWDF and MLWDF algorithm.

\section{B. Transmission Power Control Link Adaptation}

Dynamic RLC Mode Based Upon Link Adaptation to Reduce Latency and Improve Throughput in Cellular Network proposed by Ritesh S., used transmission power control link adaptation. This technique was used to improve the Long-Term Evolution (LTE) networks latency and throughput while reducing processing power. They used Block Error Rate (BER), Signal-to-Interference Ratio (SIR) and Channel Quality Indicator (CQI) as adaptation parameters to achieve their performance metrics which are throughput and delay.

The proposed technique studies the behavior of Radio Link Control (RLC) protocol with two modes of operation; 
Unacknowledgment Mode (UM) and Acknowledgment Mode (AM) in layer 2 of the UMTS and LTE network architectures. RLC comparison between UM and AM with different network condition is analyzed and adaptive RLC mode which dynamically alternates between UM and AM according to the real-time analysis of radio conditions is proposed. System delay is reduced with the decrement of layer 2 overhead along with maintaining the data reliability.

Jose A.F-S. in paper A Computationally Efficient Method for Self-Planning Uplink Power Control Parameters in LTE proposed the automatic parameter planning algorithm for the standardized power control scheme in the physical uplink shared channel (PUSCH). This algorithm can handle non-uniform outline at a low computational complexity.

The best parameter settings for each cell are calculated by aggregating adjacency level solutions. The proposed algorithm show that the average user throughput and cell edge throughput can be improved compared to the current vendor approaches, which provide network-wide uniform parameter settings. The focus of Transmission Power Control Link Adaptation is to preserve transmit power much possible while maintaining the link quality for a wide range of channel conditions [39].

\section{Packet Scheduling}

Hasibur R.C proposed an Efficient Packet Scheduling Algorithm to Improve the Performance of Cell-Edge User in LTE Network where a downlink scheduling algorithm based on modified Exponential Proportional Fairness (EXP/PF) is used to enhance cell-edge user performance. This paper considers Received Signal Strength and threshold value which varies based on the number of users in different region and distance between eNodeB and user to calculate the metric value.

This technique gives a high priority to the users in outer region. Packet scheduling is used to schedule data based on their priorities and minimizes the end to end delay [40]. Packet contains less data has higher priority compared to packet with more data [41]. If user in inner region is less than outer region, cell-edge user will get higher priority. If user in inner region exceed the number of threshold value, it will allocate RBs to the channel condition accordingly to keep up the good performance of system. It can be concluded that the proposed algorithm achieves the average user throughput by $94.5 \%$ and cell throughput by $70.6 \%$ whilst maintaining the better spectral efficiency and fairness that the existing algorithm.

On the performance of LTE downlink scheduling algorithms: A case study on edge throughput by Coskun D., proposed a new LTE downlink scheduling algorithm to enhance cell edge throughput without affecting the system throughput. Multiple scenarios were observed and in each scenario, researcher focused on parameters like number of users and cells, carrier frequency, antenna type and configuration, FFR and mobility.

The system throughput will decrease dramatically by giving additional resources to the cell edge users. To achieve higher edge throughputs without giving additional resources to the edge users, the proposed scheduler gives the priority to use the RB with high spectral efficiency and while trying to avoid the use of the RB with low spectral efficiency. This technique increases the edge throughput and fairness while limiting deteriorate cell throughput around 0 to 2 percent with respect to the other schedulers.

\section{Soft Frequency Reuse}

Soft Frequency Reuse (SFR) is used to manage the interference issues as well as improve the efficiency and quality of signal [42]. M. S. Hosain in paper Enhancing Cell-Edge Performance using Multi-Layer Soft Frequency Reuse Scheme proposed soft frequency reuse algorithm. A novel multi-layer soft frequency reuse (SFR) scheme combined with cell sectoring where the spectrum is allocated among various regions of three-cell reuse system.

In this proposed algorithm, each SFR has one outer region and inner region. The highest power is transmitted for cell-edge users while the lowest power is transmitted to the inner-most region and intermediate power between these two extreme power values are allocated to the rest of the regions. The proposed SFR algorithm shows that the spectral efficiency at cell-edge region increase by $10 \%$ which is significant for the cell-edge region. Cell sectoring enhance the overall interference thus SNR of the proposed algorithm makes further enhancement.

Soft Frequency Reuse Schemes for Heterogeneous LTE systems by Giovanni G. proposed Soft Frequency Reuse (SFR) based on three frequency segments and it is named Band Improved SFR, 3B-ISFR. This algorithm centralized Frequency Reuse Pattern (FRP) for micro cell at each level of macro cell.

The proposed algorithm is a modification of SFR scheme to HetNets taking co-tier and cross-tier interference into account. The available bandwidth will be divided into three segments where later it will allocate to edge and central part of both micro and macro cells, thus the allocation between adjacent micro and macro cells can be differentiate. This algorithm achieves a good performance in terms of overall cell outage probability along with average total cell capacity. 


\subsection{Techniques in Wireless Local Area Network (WLAN)}

Most of the researchers were focus on enhanced and improved the cell-edge performance in cellular network compared to the wireless local area network. Therefore, there is only one researcher that proposed an algorithm to solve the cell-edge performance issue in WLAN which is from Cisco.

\section{A. Dynamic Transmit Power Control}

To solve the issue regarding QoS performance in cell-edge region, Cisco designed a Voice over WLAN (VoWLAN). Dynamic Transmit Power Control (DTPC) is applied in VoWLAN to reduce any chance of one-way audio due to the unstable transmit power between Wi-Fi radio and Access Point (AP). DTPC can dynamically adjust its power for each transmission based on the conditions of network [43].

During the transmission of data, there will be packet loss if the transmit power level is not equal. By using DTPC, both phone and AP transmit using the same power level. It enables the phone to automatically modify transmit power to match with the AP's transmit power.

The proposed DTPC algorithm will be dynamic as the client moves closer or further away from the AP and it also improves the battery lifetime and the quality of audio call. This algorithm used RSSI to indicate how strong is the transmission and it aimed for high transmission of data rate in cell-edge region.

To the best of author knowledge, most of the previous researches focused on improving cell edge performance for cellular network, not much work give attention to wireless LAN network. To fill in the gap, in future the new adaptive modulation and coding scheme technique will be designed to improve the cell edge performance specifically for IEEE 802.11ac standard. Table 1 below list the summary of previous works which has been discussed in details.
Table 1: Summary of related research studies

\begin{tabular}{|c|c|c|c|c|c|}
\hline $\mathrm{Na}_{4}$ & Author & Paper (Year) & Techniqut & Standard & Results \\
\hline 1. & $\begin{array}{l}\text { Hasibur R } \\
\mathrm{C}_{2}\end{array}$ & $\begin{array}{l}\text { Erhanced } \\
\text { Quality of } \\
\text { Service of Cell } \\
\text { Edge User by } \\
\text { Extending } \\
\text { Modilied } \\
\text { Lorgest } \\
\text { Weighted Delay } \\
\text { First Algorithm } \\
\text { in LiE } \\
\text { Networis } \\
\text { Quin) }\end{array}$ & $\begin{array}{l}\text { Extended } \\
\text { Modified } \\
\text { Largest } \\
\text { Delay First } \\
\text { technigue } \\
\text { (EMII UDF) }\end{array}$ & LTE & $\begin{array}{l}\text { Achiveved } 56.23 \% \text { of } \\
\text { cell-edge } \\
\text { perfoniance } \\
\text { compared to the } \\
\text { Proportional Fanness } \\
\text { and Modilied Larget } \\
\text { Weighted Delay First } \\
\text { algorithm. Increased } \\
\text { average user } \\
\text { throughpur with } \\
\text { overall } 2325 \%\end{array}$ \\
\hline 2. & Himani L. & 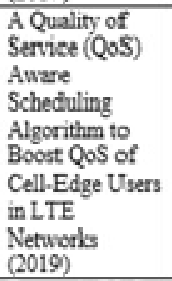 & $\begin{array}{l}\text { Improved } \\
\text { Eretesisd } \\
\text { Modified } \\
\text { Largest } \\
\text { Weiphted } \\
\text { Delay Firt } \\
\text { (IE- } \\
\text { MIINDF) }\end{array}$ & LTE & $\begin{array}{l}\text { Enhanced cell edge } \\
\text { throughput and } \\
\text { spectral effeiency by } \\
50.122 \% \text { and } 3.462 \% \\
\text { rempectively and it } \\
\text { alpo reduces PLR } \\
\text { and end to end delay } \\
\text { by } 2422 \% \text { and } \\
43.971 \% \text { respetwely }\end{array}$ \\
\hline 3 & Rutele S. & $\begin{array}{l}\text { Dynamic RLC } \\
\text { Mode Based } \\
\text { Upon Link } \\
\text { Aduptation to } \\
\text { Reduce Lateney } \\
\text { and Improve } \\
\text { Throughput in } \\
\text { Cellulis } \\
\text { Netwouk (016) }\end{array}$ & $\begin{array}{l}\text { Trangmusan } \\
\text { Power } \\
\text { Control Link } \\
\text { Adnptation }\end{array}$ & LTE & $\begin{array}{l}\text { Reduces sy } \\
\text { delay by docressing } \\
\text { lyyer } 2 \text { overbesd and } \\
\text { complexity while } \\
\text { maintaining the data } \\
\text { reliability. }\end{array}$ \\
\hline 4. & $\begin{array}{l}\text { Jose A.F- } \\
\text { S. }\end{array}$ & $\begin{array}{l}\text { A } \\
\text { Computationally } \\
\text { Efficient } \\
\text { Method for Self- } \\
\text { Planning Uplink } \\
\text { Power Control } \\
\text { Parameters in } \\
\text { LTE (2015) }\end{array}$ & $\begin{array}{l}\text { Automatic } \\
\text { parameter } \\
\text { planning } \\
\text { algorithm for } \\
\text { the } \\
\text { standardized } \\
\text { power } \\
\text { control } \\
\text { scheme in } \\
\text { the physical } \\
\text { uplink shared } \\
\text { channel } \\
\text { (PUSCH). }\end{array}$ & LTE & $\begin{array}{l}\text { Average user } \\
\text { throughput and cell } \\
\text { edge throughput can } \\
\text { be improved } \\
\text { compared to the } \\
\text { current vendor } \\
\text { approaches, which } \\
\text { provide network- } \\
\text { wide uniform } \\
\text { parameter settings }\end{array}$ \\
\hline 5. & $\begin{array}{l}\text { Hasibur } \\
\text { R.C. }\end{array}$ & $\begin{array}{l}\text { An Efficient } \\
\text { Packet } \\
\text { Scheduling } \\
\text { Algorithm to } \\
\text { Improve the } \\
\text { Performance of } \\
\text { Cell-Edge User } \\
\text { in LTE Network } \\
(2017) \\
\end{array}$ & $\begin{array}{l}\text { Downlink } \\
\text { scheduling } \\
\text { algorithm } \\
\text { based on } \\
\text { modified } \\
\text { Exponential } \\
\text { Proportional } \\
\text { Faimess } \\
\text { (EXP/PF) }\end{array}$ & LTE & $\begin{array}{l}\text { Improves the cell- } \\
\text { edge user throughput } \\
\text { up to } 7 \text { times higher } \\
\text { than other } \\
\text { algorithms. }\end{array}$ \\
\hline 6. & Coskun D. & $\begin{array}{l}\text { On the } \\
\text { performance of } \\
\text { LTE downlink } \\
\text { scheduling } \\
\text { algorithms: A } \\
\text { case study on } \\
\text { edge throughput } \\
\text { (2018) }\end{array}$ & $\begin{array}{l}\text { downlink } \\
\text { scheduling } \\
\text { algorithm }\end{array}$ & LTE & $\begin{array}{l}\text { Increases the edge } \\
\text { throughput and } \\
\text { faimess while } \\
\text { limiting degradation } \\
\text { in the cell throughput } \\
\text { between } 0 \text { to } 2 \\
\text { percent with respect } \\
\text { to the other } \\
\text { schedulers. }\end{array}$ \\
\hline 7. & $\begin{array}{l}\text { M. S. } \\
\text { Hosain| }\end{array}$ & $\begin{array}{l}\text { Enhancing Cell- } \\
\text { Edge } \\
\text { Performance } \\
\text { using Multi- } \\
\text { Layer Soft } \\
\text { Frequency } \\
\text { Reuse Scheme } \\
\text { (2015) }\end{array}$ & $\begin{array}{l}\text { Soft } \\
\text { frequency } \\
\text { reuse } \\
\text { algorithm. }\end{array}$ & LTE & $\begin{array}{l}\text { Spectral efficiency at } \\
\text { cell-edge region } \\
\text { increase by } 10 \% \\
\text { which is significant } \\
\text { for the cell-edge } \\
\text { region. }\end{array}$ \\
\hline 8. & $\begin{array}{l}\text { Giovanni } \\
\text { G. }\end{array}$ & $\begin{array}{l}\text { Soft Frequency } \\
\text { Reuse Schemes } \\
\text { for } \\
\text { Heterogeneous } \\
\text { LTE Systems } \\
(2015)\end{array}$ & $\begin{array}{l}\text { Soft } \\
\text { frequency } \\
\text { reuse } \\
\text { algorithm. }\end{array}$ & LTE-A & $\begin{array}{l}\text { Provide a good } \\
\text { performance for } \\
\text { outage probability } \\
\text { and average cell } \\
\text { capacity. }\end{array}$ \\
\hline 9. & Cisco & $\begin{array}{l}\text { Enterprise } \\
\text { Mobility } 8.1 \\
\text { Design Guide } \\
(2017)\end{array}$ & $\begin{array}{l}\text { Dynamic } \\
\text { Transmit } \\
\text { Power } \\
\text { Control } \\
\text { (DTPC) }\end{array}$ & WLAN & $\begin{array}{l}\text { Improves the battery } \\
\text { lifetime and the } \\
\text { quality of audio call }\end{array}$ \\
\hline
\end{tabular}




\section{PROPOSED TECHNIQUE}

To the best of author knowledge, most of the previous researches focused on improving cell edge performance for cellular network. However, there is only one proposed technique from Cisco; Enterprise Mobility 8.1 Design Guide where it focused on Wireless LAN edge performance. Due to this research gap, the author proposed Adaptive Modulation and Coding Scheme which adapt the transmission data rate to improve the cell edge performance for IEEE 802.11ac standard Wireless LAN. Table below summarize the related research studies.

\subsection{Adaptive Modulation \& Coding Scheme}

Adaptive Modulation and Coding Scheme is based on channel estimation [44] where channel state information (CSI) such as SNR, BER, Delay and Queue Length need to be used to describe how signal propagates from transmitter to receiver. System capacity, peak data rate and coverage reliability can be improved by using adaptive modulation and coding where this technique modify the signal transmitted to a particular user to account for the signal quality variation. To optimize the link performance, communication standards like IEEE 802.11, IEEE 802.15, IEEE 802.15, EDGE, LTE, HSDPA and have applied AMC as their fundamental technique [45]. In addition to this, the link adaptation technique changes both protocol and signal parameters as link conditions change [46].

In a good radio link condition, small amount of error correction is used, along with a high-level efficient modulation. Thus, higher data throughput in radio channel can be obtained. While in a poor radio link condition, data throughput is lower where this is due to large amount of error correction, low-level, and robust modulation scheme.

For a good network performance, link adaptation is used as this algorithm reacts to physical channel condition where it changes the link parameters like modulation scheme, coding scheme or transmission power [47].

\subsection{Transmission Rate Adaptation}

Rate adaptation dynamically change the transmission rate to adapt to the time-varying and location-dependents channel quality in order to maximize the channel efficiency [48]. Adaptation of transmission data rate is due to signal fading that cause by distance, tradeoff between data-rate and range and interference from other sources. Radio wave is easily affected by interference such as fading and path loss. Higher modulation scheme with lower amount of error correction will provide a good radio channel, where higher amount of throughput can be achieved. While lower modulation scheme with high amount of error correction will affect the performance of radio channel to low data throughput.

Table 3 shows the number of data rate in each modulation scheme for one spatial stream (SS). The highest modulation scheme is 256-Quadrature Amplitude Modulation which produce the highest data rate and is used in a good radio link condition.

Table 2: IEEE 802.11ac WLAN Modulation and coding schemes (MCS) for single spatial stream [49]

\begin{tabular}{|c|c|c|c|c|c|c|}
\hline \multicolumn{3}{|c|}{} & \multicolumn{4}{|c|}{ Data Rate in Mbps } \\
\hline MCS & Modulation & Coding Rate & $20 \mathrm{MHz}$ & $40 \mathrm{MHz}$ & $80 \mathrm{MHz}$ & $160 \mathrm{MHz}$ \\
\hline 0 & BPSK & $1 / 2$ & 6.5 & 13.5 & 29.3 & 58.5 \\
1 & QPSK & $1 / 2$ & 13 & 27 & 58.5 & 117 \\
2 & QPSK & $3 / 4$ & 19.5 & 40.5 & 87.8 & 175.5 \\
3 & $16-\mathrm{QAM}$ & $1 / 2$ & 26 & 54 & 117 & 234 \\
4 & $16-\mathrm{Q} \mathrm{AM}$ & $3 / 4$ & 39 & 81 & 175.5 & 351 \\
5 & $64-\mathrm{QAM}$ & 23 & 52 & 108 & 234 & 468 \\
6 & $64-\mathrm{QAM}$ & $3 / 4$ & 58.5 & 121.5 & 263.3 & 526.5 \\
7 & $64-\mathrm{QAM}$ & $5 / 6$ & 65 & 135 & 292.5 & 585 \\
8 & $256-\mathrm{QAM}$ & $3 / 4$ & 78 & 162 & 351 & 702 \\
9 & $256-\mathrm{QAM}$ & $5 / 6$ & $\mathrm{~N} / \mathrm{A}$ & 180 & 390 & 780 \\
\hline
\end{tabular}

\subsection{Flowchart of proposed algorithm}

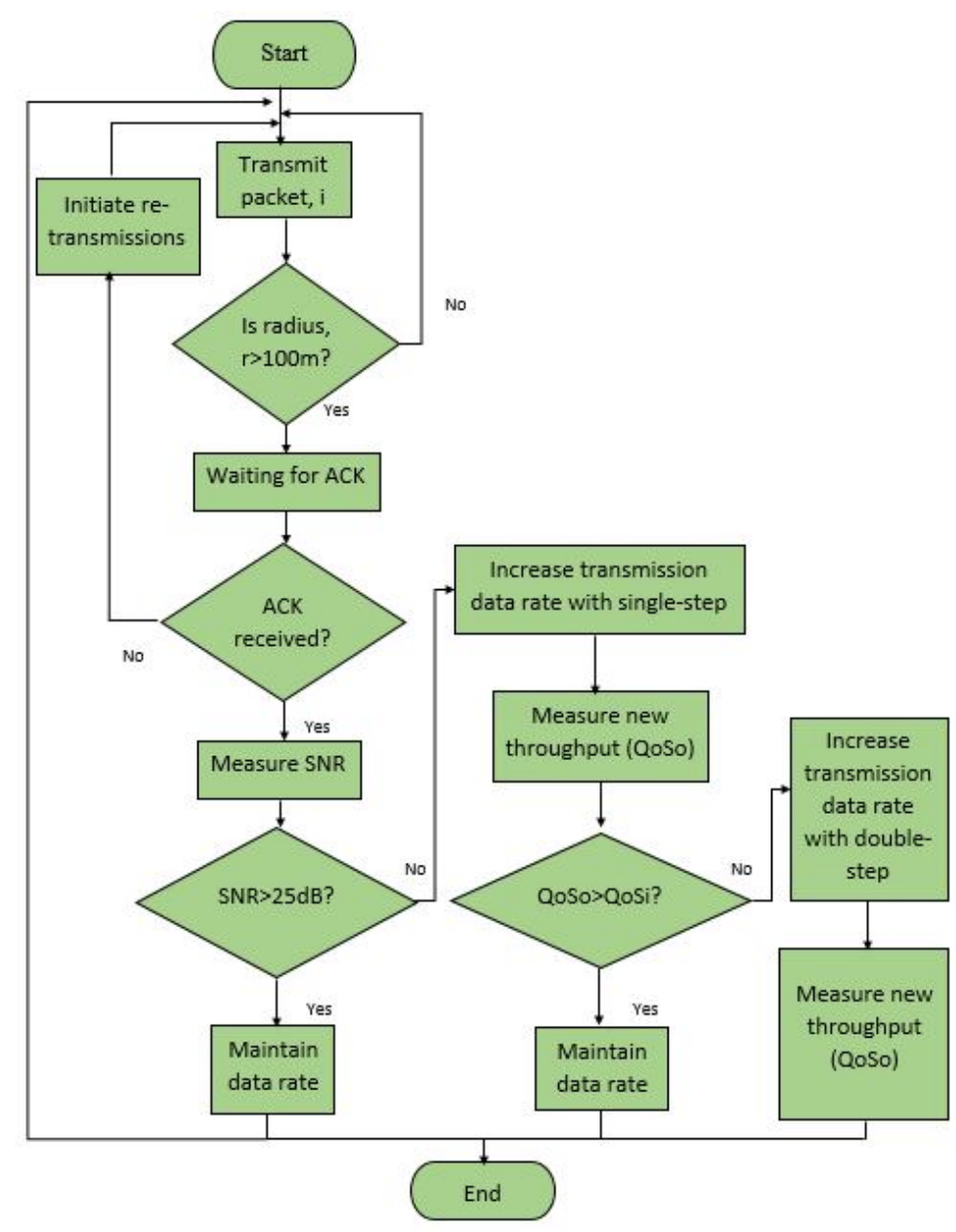

Figure 2: Flowchart of the proposed technique 
Nur Syazwani Mustaffa et al., International Journal of Advanced Trends in Computer Science and Engineering, 9(1.4), 2020,592 - 600

Figure 2 above shows the idea of the proposed transmission rate adaptation technique. The flow starts with the transmission of packet, i from transmitter to the receiver. In order to determine whether the packet is transmitted in center or edge region, measurement of radius will be taken. An area is said to be located in a cell-edge if it is more than 100 meter from the Access Point (AP). The transmitter will then wait for the acknowledgment (ACK) packet before it can proceed to the next step. If there is no ACK packet received, the transmitter will initiate re-transmission of the packet via the CSMA/CA procedure. Packet loss is due to these two major problems which are the error channel condition and collisions. For this proposed algorithm, error channel condition will be considered so the packet loss is due to channel error in transmission rate adaptation. If the ACK packet is successfully received, the performance metric of the QoS which is the throughput (QoSi) will be recorded. These initial QoS performances (QoSi) will then be compared to the QoS performance after the execution of the rate adaptation. Rate estimators or packet loss can be used to determine the wireless channel condition [50]. In this project, SNR is used as rate estimator to indicate the channel condition. Rate adaptation algorithm will be adapted according to the SNR value to optimize the throughput. If the SNR value recorded is greater than $25 \mathrm{~dB}$, it indicates a good channel condition, thus the data rate is maintained. If the SNR value is less than 25 $\mathrm{dB}$, it indicates a bad channel condition which means that the packet might be loss in the cell-edge area. This issue can be solved by increasing the rate adaptation thus improve the QoS performance. New measurement of QoS (QoSa) is recorded after the adaptation process and these new value will then be compared with the initial QoS (QoSi). In the case of the new QoS (QoSa) greater than initial QoS (QoSi), the system will maintain the data rate. While for the case where initial QoS (QoSi) value is greater than new QoS (QoSo), the rate adaptation will be increase with double step until the new QoS value is improved than the original QoS measurements. This transmission data rate adaptation process will be repeated until the last number of packets. The QoS performance that will be analyze at cell-edge region are throughput, fairness and spectral efficiency.

\section{CONCLUSION}

This paper, A Review on Techniques to Improve the Cell Edge Performance for Wireless Networks, reviewed published literature which focus to boost the cell-edge performance for both cellular and wireless local area networks. Based on the review, researches have come up with techniques to solve the cell-edge performance where this issues have been an interesting topic to solve. Researchers in this field proposed few techniques to improve the overall system performance so that both users in center and edge region experience the same excellent services, but most of the techniques were focusing on cellular network performance. Due to this issue, the author proposed Adaptive Modulation and Coding Scheme that adapt transmission data rate for Wireless LAN specifically in IEEE 802.11ac standard. This proposed technique is expected to enhance the QoS performance of user in cell-edge region in terms of throughput.

\section{ACKNOWLEDGEMENT}

This research was supported under budget of Fundamental Research Grant Scheme (FRGS), 600-IRMI/FRGS 5/3 (327/2019)

\section{REFERENCES}

1. M. Dahiya, Evolution of Wireless LAN in Wireless Networks, Int. J. Comput. Sci. Eng., vol. 9, no. 3, 2017.

2. S. Y. M. Bandiri, R. M. S. Braga, and D. H. Spadoti, Analytical comparison of the performance of adaptive modulation and coding in wireless network under rayleigh fading, J. Microwaves, Optoelectron. Electromagn. Appl., vol. 16, no. 3, pp. 723-735, 2017.

3. R. Karmakar, S. Chattopadhyay, and S. Chakraborty, Dynamic link adaptation for High Throughput wireless access networks, Int. Symp. Adv. Networks Telecommun. Syst. ANTS, vol. 2016-Febru, pp. 1-6, 2016.

4. T. N. Do, D. Benevides, T. Q. Duong and B. An, Improving the Performance of Cell-Edge Users in MISO-NOMA Systems Using TAS and SWIPT-based Cooperative Transmissions, vol. 2400, no. c, pp. 1-14, 2017.

5. H. R. Chayon, K. Bin Dimyati, H. Ramiah, and A. W. Reza, Enhanced Quality of Service of Cell-Edge User by Extending Modified Largest Weighted Delay First Algorithm in LTE Networks, pp. 1-14, 2017.

6. H. Lodwal, A. Yadav, and M. Panchal, A quality of service (QoS) aware scheduling algorithm to boost QoS of cell-edge users in LTE networks, Int. $J$. Recent Technol. Eng., vol. 8, no. 2, pp. 2589-2594, 2019.

7. E. Ab and R. S. Carbajo, Dynamic RLC Mode Based Upon Link Adaptation to Reduce Latency and Improve Throughput in Cellular Networks, pp. 2-7, 2016.

8. J. Á. Fernández-Segovia, S. Luna-Ramírez, M. Toril, A. B. Vallejo-Mora, and C. Úbeda, A computationally efficient method for self-planning uplink power control parameters in LTE, Eurasip J. Wirel. Commun. Netw., vol. 2015, no. 1, 2015.

9. H. R. Chayon, K. Dimyati, and H. Ramiah, An Efficient Packet Scheduling Algorithm to Improve the Performance of Cell-Edge User in LTE 
Network, no. Micc, pp. 28-30, 2017.

10. O. G. Uyan and V. Cagri, Computer Standards \& Interfaces On the performance of LTE downlink scheduling algorithms: A case study on edge throughput, vol. 59, no. November 2017, pp. 96-108, 2018.

https://doi.org/10.1016/j.csi.2018.03.001

11. M. S. Hossain, F. Tariq, and G. A. Safdar, Enhancing cell-edge performance using multi-layer soft frequency reuse scheme.

12. Y. Yu, E. Dutkiewicz, X. Huang, M. Mueck, and G. Fang, Performance analysis of soft frequency reuse for inter-cell interference coordination in LTE networks, Isc. 2010 - 2010 10th Int. Symp. Commun. Inf. Technol., pp. 504-509, 2010.

13. Cisco, Enterprise Mobility 8.1 Design Guide, Enterp. Mobil. 8.1 Des. Guid., no. 6387, pp. 1-484, 2017.

14. Y. Xin, M. Ma, Z. Zhao, and B. Jiao, Co-channel interference suppression techniques for full duplex cellular system, China Commun., vol. 12, pp. 18-27, 2015.

15. H. Lodwal, A. Yadav, and M. Panchal, A Novel Algorithm to Improve Quality of Service of Cell Edge Users in LTE. Springer Singapore.

16. D. Deng et al., IEEE 802 . 11ax : Highly Efficient WLANs for Intelligent Information Infrastructure, no. December, pp. 52-59, 2017.

17. J. P. Rula, F. E. Bustamante, and M. Steiner, Cell spoting: Studying the role of cellular networks in the internet, Proc. ACM SIGCOMM Internet Meas. Conf. IMC, vol. Part F1319, pp. 191-204, 2017.

18. J. Engineering, Advanced Trends in Computer Science Enhancing Performance of IoT Networks through High Performance Computing, vol. 8, no. 3, 2019.

https://doi.org/10.30534/ijatcse/2019/17832019

19. Next Generation Mobile Networks Alliance 5G Initiative, 5G White Paper, A Deliv. by NGMN Alliance, p. 124, 2015.

20. S. Yadav and S. Singh, Review Paper on Development of Mobile Wireless Technologies ( $1 \mathbf{G}$ to 5G ), Int. J. Comput. Sci. Mob. Comput., vol. 7, no. 5, pp. 94-100, 2018.

21. I. Khan, H. Nawaz, M. M. Rind, K. Kumar, M. A. Chahajro, and A. Mailto, Comparative Study of Existing and Forthcoming WLAN Technologies, Int. J. Comput. Sci. Netw. Secur., vol. 18, no. 4, pp. 101-108, 2018.

22. Q. Qu, B. Li, M. Yang, and Z. Yan, Survey and Performance Evaluation of the Upcoming Next Generation WLAN Standard - IEEE 802 . 11ax.

23. M. S. Afaqui, E. Garcia-Villegas, and E. Lopez-Aguilera, IEEE 802.11ax: Challenges and Requirements for Future High Efficiency WiFi, IEEE Wirel. Commun., vol. 24, no. 3, pp. 130-137, 2016.
24. A. S. Mohd Anuar, W. N. W. Muhamad, D. Mohd Ali, S. S. Sarnin, and N. A. Wahab, A review on link adaptation techniques for energy efficiency and QoS in IEEE802.11 WLAN, Indones. J. Electr. Eng. Comput. Sci., vol. 17, no. 1, p. 331, 2020.

25. D. Deng, S. Lien, J. Lee, and K. Chen, On Quality-of-Service Provisioning in IEEE 802 . 11ax WLANs, vol. 3536, no. c, pp. 1-20, 2016.

26. S. R. Chaudhary, A. J. Patil, and A. V. Yadao, WLAN-IEEE 802.11ac: Simulation and performance evaluation with MIMO-OFDM, Conf. Adv. Signal Process. CASP 2016, pp. 440-445, 2016.

27. F. Tramarin, S. Vitturi, M. Luvisotto, and A. Zanella, On the Use of IEEE 802.11n for Industrial Communications, IEEE Trans. Ind. Informatics, vol. 12, no. 5, pp. 1877-1886, 2016.

28. CISCO, 802 . 11ac: The Fifth Generation of Wi-Fi, Cisco Public Inf., pp. 1-25, 2014.

29. M. L. Chaudhary, M. P. Verma, M. A. Jangid, and A. Vyas, IEEE 802 . 11ac: Next Generation High Speed Wireless LAN Technology, pp. 2-6, 1956.

30. K. Features, Introduction to 802.11ax High-Efficiency Wireless Improving User Throughput in Dense User Environments Introduction Key Features and Applications, no. 1999, pp. 1-19, 2020.

31. Z. Machrouh and A. Najid, High efficiency IEEE 802.11ax MU-MIMO and frame aggregation analysis, Proc. - 2018 Int. Conf. Adv. Commun. Technol. Networking, CommNet 2018, pp. 1-5, 2018.

32. E. Muhammad, U. Ghori, E. Abdul, A. Khan, B. Naeem, and A. Sheikh, Optimized Dynamic Cell Selection Approach towards Intercell Interference Reduction for Cell-edge Users In LTE-A Network, no. 1, pp. 1-7, 2017.

33. H. Moura, G. V. C. Bessa, M. A. M. Vieira, and D. F. Macedo, Ethanol: Software defined networking for 802.11 Wireless Networks, Proc. 2015 IFIP/IEEE Int. Symp. Integr. Netw. Manag. IM 2015, pp. 388-396, 2015.

34. G. Sun, H. Zhang, and G. Liu, User Demand Aware Soft-Association Control in Ultra-Dense Small Cell Networks, Proc. - Conf. Local Comput. Networks, LCN, pp. 651-654, 2016.

35. C. Malarvizhi and V. Nithya, Enhancing Cell Edge Performance in Cellular Mobile System, Int. J. Futur. Gener. Commun. Netw., vol. 8, no. 6, pp. 49-58, 2015.

36. P. Yang, J. Yan, D. Wu, and N. Shu, A delay-aware scheduling algorithm for enhancing video services QoS in LTE system, MOBIMEDIA 2015 - 8th Int. Conf. Mob. Multimed. Commun., 2015.

37. A. Busson and I. Lahsen-Cherif, Impact of Resource Blocks Allocation Strategies on Downlink Interference and SIR Distributions in LTE Networks: A Stochastic Geometry Approach, 
Wirel. Commun. Mob. Comput., vol. 2018, 2018.

38. D. Nguyen, H. Nguyen and E. Renault., A new Channel-and QoS-Aware Scheduling Scheme for Real-time Services in LTE Network, Sept 2016.

39. T. M. Kusuma, R. Rahmanto, and E. Haryatmi, Adaptive power link adaptation on DVB-T system based on picture quality feedback, Int. J. Electr. Comput. Eng., vol. 9, no. 4, pp. 3121-3129, 2019.

40. V. Akila, T. Sheela, and G. A. Macriga, Efficient packet scheduling technique for data merging in wireless sensor networks, China Commun., vol. 14, no. 4, pp. 35-46, 2017.

https://doi.org/10.1109/CC.2017.7927575

41. S. Ghosh and A. Banerjee, Anycast Scheduler For Ad Hoc Networks, vol. 4, no. 2, pp. 15-21, 2015.

42. G. Saini, Enhancing Cell Throughput \& Area Spectral Efficiency Using Two Level Soft Frequency Reuse Technique, Int. J. Innov. Technol. Explor. Eng., vol. 8, no. 9, pp. 1524-1530, 2019.

43. P. P. Priyesh and S. K. Bharti, Dynamic transmission power control in wireless sensor networks using P-I-D feedback control technique, 2017 9th Int. Conf. Commun. Syst. Networks, COMSNETS 2017, pp. 306-313, 2017.

44. Z. Li, H. Li, and Q. Zhang, Research and Improvement of Adaptive Modulation and Coding Scheme for VDE-TER System Research and Improvement of Adaptive Modulation and Coding Scheme for VDE-TER System, IWAACE 2020, Journal of Physics: Conference Series, p. 2, 2020.

45. M. Lopez-Benitez, Throughput performance models for adaptive modulation and coding under fading channels, IEEE Wirel. Commun. Netw. Conf. WCNC, vol. 2016-Septe, no. Wcnc, pp. 0-5, 2016.

46. J. J. Popoola, D. E. Okhueleigbe, and I. A. Alimi, Link Adaptation for Microwave Link using both MATLAB and Path-Loss Tool, vol. 4, no. 4, 2016.

47. H. J. Zhu and D. Kidston, The impact of link adaptation on Wifi 802.11N, 2016 IEEE Int. Conf. Netw. Archit. Storage, NAS 2016 - Proc., 2016.

48. C. Ahn and S. Chung, Enhancing WLAN Performance with Rate Adaptation Considering Hidden Node Effect, vol. 2015, 2015.

49. B. Bellalta and K. Kosek-Szott, AP-initiated multi-user transmissions in IEEE 802.11ax WLANs, Ad Hoc Networks, vol. 85, no. February 2017, pp. 145-159, 2019.

50. A. Anitha and J. Jayakumari, Rate adaptation schemes in WLANs, Int. J. Enterp. Netw. Manag., vol. 7, no. 3, pp. 191-206, 2016. 